\title{
Postsynaptic Density-93 Interacts with the $\delta 2$ Glutamate Receptor Subunit at Parallel Fiber Synapses
}

\author{
Katherine W. Roche, ${ }^{1}$ C. Dune Ly, ${ }^{1}$ Ronald S. Petralia, ${ }^{1}$ Ya-Xian Wang, ${ }^{1}$ Aaron W. McGee, ${ }^{2}$ David S. Bredt, ${ }^{2}$ \\ and Robert J. Wenthold 1 \\ 1 Laboratory of Neurochemistry, National Institute on Deafness and Other Communication Disorders, National Institutes of \\ Health, Bethesda, Maryland 20892, and 2Department of Physiology and Programs in Biomedical Sciences and \\ Neuroscience, University of California at San Francisco School of Medicine, San Francisco, California 94143-0444
}

\begin{abstract}
The glutamate receptor subunit $\delta 2$ has a unique distribution at the parallel fiber-Purkinje cell synapse of the cerebellum, which is developmentally regulated such that $\delta 2$ occurs at both parallel fiber synapses and climbing fiber synapses early in development but is restricted to parallel fiber synapses in adult animals. To identify proteins that might be involved in the trafficking or docking of $\delta 2$ receptors, we screened a yeast two-hybrid library with the cytosolic $C$ terminus of $\delta 2$ and isolated a member of the postsynaptic density (PSD)-95 family of proteins, which are known to interact with the extreme C termini of NMDA receptors. We find that $\delta 2$ binds specifically to PSD-93, which is enriched in Purkinje cells. In addition, PSD-93
\end{abstract}

clusters $\delta 2$ when they are coexpressed in heterologous cells, and clustering is disrupted by point mutations of $\delta 2$ that disrupt the $\delta 2-P S D-93$ interaction. Ultrastructural localization of PSD-93 and $\delta 2$ shows they are colocalized at parallel fiber synapses; however, PSD-93 also is present at climbing fiber synapses of the adult rat, where $\delta 2$ is not found, indicating that the presence of PSD-93 alone is not sufficient for determining the synaptic expression of $\delta 2$.

Key words: glutamate receptor; receptor targeting; yeast two-hybrid; synaptic anchor; cerebellum; synaptic receptor regulation
Ionotropic glutamate receptors comprise three subtypes, and each contains multiple subunits that assemble to form functional receptor complexes: NMDA (NR1, NR2A-D), AMPA (GluR14), and kainate (GluR5-7; KA1-KA2) (Hollmann and Heinemann, 1994). A fourth subtype, $\delta$, has two known subunits ( $\delta 1$ and 82) (Yamazaki et al., 1992; Lomeli et al., 1993). Although both $\delta 1$ and $\delta 2$ resemble ionotropic glutamate receptor subunits based on sequence similarity, neither forms functional channels when expressed in Xenopus oocytes or mammalian cells. For this reason, far less is known about the functional role of $\delta$ glutamate receptors than the more extensively characterized NMDA, AMPA, and kainate receptors. Despite their limited functional characterization, genetic studies have identified a critical role for $\delta 2$ in cerebellar function. $\delta 2$ has a unique distribution, being highly expressed in cerebellar Purkinje cells (Araki et al., 1993), where it is specifically found postsynaptic to parallel fiber synapses (Landsend et al., 1997; Zhao et al., 1997). Because the locus of cerebellar long-term depression (LTD) is the parallel fiber-Purkinje cell synapse, there has been substantial speculation that $\delta 2$ might be the glutamate receptor involved in that paradigm of synaptic plasticity. Indeed, mice lacking $\delta 2$ display impaired LTD (Kashiwabuchi et al., 1995), and LTD in cultured Purkinje cells

\footnotetext{
Received Dec. 3, 1998; revised Feb. 4, 1999; accepted Feb. 5, 1999.

This work was supported by the Pharmacology Research Associate Program (PRAT program, National Institute of General Medical Sciences, National Institutes of Health) (K.W.R.), the National Institute on Deafness and Other Communication Disorders intramural program (R.J.W.), and by National Association for Research on Schizophrenia and Depression and the National Institutes of Health (GM36017) (D.S.B.).

Correspondence should be addressed to Dr. Katherine W. Roche, National Institute on Deafness and Other Communication Disorders, National Institutes of Health, Building 36, Room 5D08, Bethesda, MD 20892. E-mail address: rochek@nidcd.nih.gov

Copyright (C) 1999 Society for Neuroscience $\quad 0270-6474 / 99 / 193926-09 \$ 05.00 / 0$
}

requires the $\delta 2$ subunit (Hirano et al., 1995; Jeromin et al., 1996). Interest in $\delta 2$ has increased recently because of the exciting discovery that the phenotype of the Lurcher mouse, which is characterized by degeneration of cerebellar Purkinje cells, is caused by a point mutation in the third transmembrane domain of $\delta 2$ (Zuo et al., 1997). This gain-of-function mutation results in a constitutively open $\delta 2$ channel, allowing a large inward current that leads to cell death.

For glutamate receptors to function normally, they must be appropriately targeted to, and retained at, specific postsynaptic sites. Synaptic enrichment of receptors is a complex process requiring many proteins to regulate trafficking of the receptors to dendritic spines and docking at the postsynaptic density (PSD). This complexity is well illustrated by the differential targeting of the $\delta 2$ receptor subunit in Purkinje cells. Early in development, $\delta 2$ is found at both parallel fiber and climbing fiber synapses but, in the adult, $\delta 2$ is restricted to the parallel fiber synapse (Landsend et al., 1997; Zhao et al., 1997). Other ionotropic and metabotropic glutamate receptors are seen at both synaptic populations and do not change with development (Zhao et al., 1998). Very little is known about the mechanisms underlying the differential targeting of receptors; however, recent studies have identified a critical role for the cytoskeleton in the docking and clustering of receptors at postsynaptic sites. The best characterized postsynaptic cytoskeletal anchors are the PSD-95 family of proteins, which are members of the larger family of membrane-associated guanylate kinases (MAGUKs). PSD-95/synapse-associated protein (SAP)90, PSD-93/chapsyn-110, SAP-97/human discs large, and SAP102 all contain three conserved PSD-95/discs large/zona occludens-1 (PDZ) domains, an SH3 domain, and a guanylate kinase domain, and all bind to Shaker $\mathrm{K}^{+}$channels and NMDA receptors (Sheng and Kim, 1996; Ziff, 1997; Craven and Bredt, 
1998). The binding of PSD-95 and related proteins to NMDA receptors and Shaker $\mathrm{K}^{+}$channels requires the last six amino acids of the channels. This region is characterized by a $\mathrm{T} / \mathrm{SxV}$ binding motif (see Fig. 1) in which the terminal amino acid (0 position) and the residue at the -2 position are critical for binding.

In the present study, we used the $\delta 2 \mathrm{C}$ terminus to screen a rat brain cDNA library using the yeast two-hybrid system to identify proteins that may be involved in the trafficking and/or synaptic localization of $\delta 2$. We isolated a member of the PSD-95 family of proteins and, after subsequent characterization, demonstrated that $\delta 2$ can bind to PSD-93, PSD-95, and SAP-97. PSD-93 binds to $\delta 2$ in several independent assays, induces clustering of $\delta 2$ when the two proteins are coexpressed in heterologous cells, and colocalizes with $\delta 2$ at the ultrastructural level in parallel fibers of Purkinje cells. Unlike $\delta 2$, PSD-93 is expressed at climbing fiber synapses, as well as parallel fiber synapses, suggesting that the PSD-95 family of proteins is not responsible for the initial targeting of receptors to specific synapses but more likely anchors or docks receptors targeted by other mechanisms.

\section{MATERIALS AND METHODS}

cDNA constructs. $\delta 2$ and $\delta 1$ cDNAs in mammalian expression vectors were generously provided by P. Seeburg (Max Planck Institute, Heidelberg, Germany). The PSD-93 cDNA was isolated as described previously (Brenman et al., 1996b). The $\delta 2$ wild-type (WT) C terminus (amino acids 852-1008), $\delta 1$ WT C terminus (amino acids 852-1009), and $\delta 2$ truncated $\mathrm{C}$ terminus (amino acids 852-1004) were amplified using PCR and subcloned into the GAL 4 DNA binding domain vector pGBT9 using EcoRI and BamHI sites. Point mutations of $\delta 2$ were produced using the QuikChange mutagenesis kit (Stratagene, La Jolla, CA), amplified by PCR, and then inserted into pGBT9. The various PDZ constructs of PSD-95 were amplified using PCR and subcloned into the GAL 4 activation domain vector pGAD 424 using EcoRI and BamHI sites. The sequences of all PCR products were confirmed by automated sequence analysis.

Screening of the yeast two-hybrid library. The $\delta 2 \mathrm{WT} \mathrm{C}$ terminus (amino acids 852-1008) was used to screen a rat brain cDNA library in the activation domain vector pGAD 10 (Clontech, Palo Alto, CA). Approximately 1.94 million clones were screened, yielding five positives. The positive interactors were verified by restreaking and assaying for growth on histidine-deficient plates and $\beta$-galactosidase activity.

Yeast two-hybrid assays. Constructs in GAL 4 DNA binding domain vectors and constructs in GAL 4 activation domain vectors were cotransformed into HF7c yeast cells according to the manufacturer's protocol (Clontech). The yeast cells were plated onto synthetic dextrose plates lacking tryptophan and leucine and allowed to grow for $\sim 3 \mathrm{~d}$. Colonies were then resuspended in $10 \mathrm{~mm}$ tris and $1 \mathrm{~mm}$ EDTA, $\mathrm{pH} 8.0$, and restreaked on dextrose plates lacking tryptophan and leucine and also onto plates lacking tryptophan, leucine, and histidine (His-deficient plates). Growth on His-deficient plates was scored on a - to +++ scale, comparing cotransformations that yielded equivalent growth on plates lacking tryptophan and leucine but containing histidine. Colony lifts were performed on His-deficient plates, and $\beta$-galactosidase activity was assayed using $\mathrm{X}$-gal. Color intensity was scored from - to +++ .

Cell culture and transfections. Human embryonic kidney (HEK)-293 cells were grown on $10 \mathrm{~cm}$ dishes for biochemical analyses. HEK-293 cells were transfected with PSD-93 $(5 \mu \mathrm{g})$ and $\delta 2 \mathrm{WT}$ or mutant cDNAs $(5 \mu \mathrm{g})$ using the calcium phosphate coprecipitation method (Blackstone et al., 1992). Transfected cells were analyzed $36 \mathrm{hr}$ after transfection.

HeLa cells were grown on glass coverslips in six-well tissue culture dishes for immunofluorescence microscopy. HeLa cells were transfected with PSD-93 cDNA, along with $\delta 2 \mathrm{WT}$ or mutant cDNAs ( $4 \mu \mathrm{g}$ total per well of six-well dish) using the calcium phosphate coprecipitation method (Blackstone et al., 1992). Transfected cells were analyzed $24 \mathrm{hr}$ after transfection.

Antibodies. Antibodies against $\delta 1 / 2$ (Mayat et al., 1995), GluR2/3 (Wenthold et al., 1992), and PSD-93 (Brenman et al., 1996b) have been characterized previously. Monoclonal antibodies raised against PSD-95 (Kornau et al., 1995) were generously provided by M. Kennedy (California Institute of Technology, Pasadena, CA). We refer to these anti- bodies as PSD-93/95 because they recognize PSD-93 (see Fig. 5), in addition to PSD-95.

Immunocytochemistry. Transfected HeLa cells grown on coverslips were washed in PBS, fixed in 4\% paraformaldehyde in PBS for $20 \mathrm{~min}$, washed in PBS, and permeabilized in $0.25 \%$ Triton X-100 in PBS for 5 min. The coverslips were washed in PBS and incubated with primary antibodies in PBS containing 3\% normal goat serum (NGS) (PSD-93/95 monoclonal antibodies, $1: 1000 ; \delta 1 / 2$ affinity purified antibodies, $1 \mu \mathrm{g} / \mathrm{ml}$ ) for $1-2 \mathrm{hr}$ at room temperature, washed in PBS, and incubated with FITC anti-mouse and rhodamine anti-rabbit secondary antibodies in PBS containing 3\% NGS (1:500; Jackson ImmunoResearch, West Grove, PA) for $30 \mathrm{~min}$ at room temperature, washed three times in PBS, and mounted with Vectashield mounting media (Vector Laboratories, Burlingame, CA).

Immunoprecipitations and immunoblot analysis. Transfected HEK-293 cells were collected in PBS and pelleted by centrifugation. The pellets were resuspended in lysis buffer without detergent $[50 \mathrm{~mm}$ Tris- $\mathrm{HCl}, \mathrm{pH}$ 7.5, containing protease inhibitors (PMSF, $0.5 \mathrm{~mm}$; leupeptin, $1 \mu \mathrm{g} / \mathrm{ml}$; pepstatin, $1 \mu \mathrm{g} / \mathrm{ml}$; and EDTA, $2.5 \mathrm{~mm})$ ] and sonicated, and Triton X-100 was added to a final concentration of $1 \%$. The particulate fraction was removed by centrifugation, and the supernatant was incubated with $10 \mu \mathrm{g}$ of affinity purified $\delta 1 / 2$ antibodies or $3 \mu \mathrm{l}$ of PSD-93 guinea pig (GP) antisera bound to protein A Sepharose for $1.5 \mathrm{hr}$ or longer. The beads were washed three times with lysis buffer containing $0.1 \%$ Triton X-100, and proteins were eluted by boiling in SDS-PAGE sample buffer.

Frozen rat cerebella were homogenized in lysis buffer without detergent containing protease inhibitors (see above) in a Polytron, and either Triton X-100 or deoxycholate (DOC) was added to a final concentration of $1 \%$. Triton X-100-solubilized tissue was incubated for $30 \mathrm{~min}$ at $4^{\circ} \mathrm{C}$, and DOC-solubilized tissue was incubated for $30 \mathrm{~min}$ at $37^{\circ} \mathrm{C}$. The insoluble fraction in each preparation was removed by centrifuging at $100,000 \times g$ for $30 \mathrm{~min}$. The DOC samples were then dialyzed overnight against $50 \mathrm{~mm}$ Tris- $\mathrm{HCl}, \mathrm{pH} 7.5$, containing $0.1 \%$ Triton $\mathrm{X}-100$ and centrifuged again to remove insoluble material. Detergent-soluble supernatants were incubated with $10 \mu \mathrm{g}$ of affinity purified $\delta 1 / 2$ antibodies or $3 \mu \mathrm{l}$ of PSD-93 GP antisera bound to protein A Sepharose or to protein A Sepharose alone overnight. The beads were washed three times with lysis buffer containing $0.1 \%$ Triton $\mathrm{X}-100$, and proteins were eluted by boiling in SDS-PAGE sample buffer for 3-5 min.

SDS-PAGE was performed using $4-20 \%$ gradient gels. Proteins were resolved and transferred onto polyvinylidene difluoride (Immobilon; Millipore, Bedford, MA) membranes and subjected to immunoblot analysis using the antibodies indicated in the figure legends and the appropriate secondary antibodies. Results were visualized using enhanced chemiluminescence (Pierce, Rockford, IL).

Chemical cross-linking. Cerebellar membranes were cross-linked with

$\begin{array}{rr}\delta 1 & \text { SHGTSI } \\ \text { S2 } & \text { DRGTSI } \\ \text { NR2A } & \text { SIESDV } \\ \text { NR2B } & \text { SIESDV } \\ \text { NR2C } & \text { SLESEV } \\ \text { NR2D } & \text { SLESEV } \\ \text { GluR1 } & \text { LGATGL } \\ \text { ShA } & \text { SVETDV } \\ \text { ShB } & \text { SVETDV } \\ \text { KV1.4 } & \text { AVETDV } \\ & \\ \text { Kir2.3 } & \text { RRESAI }\end{array}$

Figure 1. Alignment of the $\mathrm{C}$ termini of glutamate receptors and $\mathrm{K}^{+}$ channels known to interact with the PSD-95 family of proteins. The terminal six amino acids of each protein are listed with the amino acids in the 0 and -2 positions indicated in bold type. 
Figure 2. The C-terminal TxI motif from $\delta 2$ or $\delta 1$ binds to PSD-93. $A$, Yeast HF7c cells were cotransformed with expression vectors encoding various GAL 4 DNA binding domain fusion proteins and the PSD-93-GAL 4 activation domain fusion protein. The PSD-93 construct includes PDZ domains I and II. Each transformation mixture was plated on synthetic dextrose plates lacking tryptophan and leucine. Interaction was measured by the filter assay (Clontech) as described previously (Fields and Song, 1989) and by growth on histidine-deficient media. Data are representative of experiments repeated two times with similar results. $B$, A schematic of $\delta 2$ that indicates the last six amino acids containing the conserved TxI motif and the critical amino acids in the 0 and -2 positions.

\section{A}

Gal 4 DNA binding hybrid$$
\delta 1 \text { WT C-terminus (851-1009) }
$$$$
\delta 2 \text { truncated C-terminus (852-1002) }
$$$$
\delta 2 \text { C-terminus (852-1008) T } 1006 \mathrm{~S}
$$$$
\delta 2 \text { C-terminus (852-1008) T } 1006 \mathrm{P}
$$$$
82 \text { C-terminus (852-1008) | } 1008 \mathrm{~V}
$$$$
\delta 2 \text { C-terminus (852-1008) I } 1008 \mathrm{~A}
$$$$
\text { B }
$$

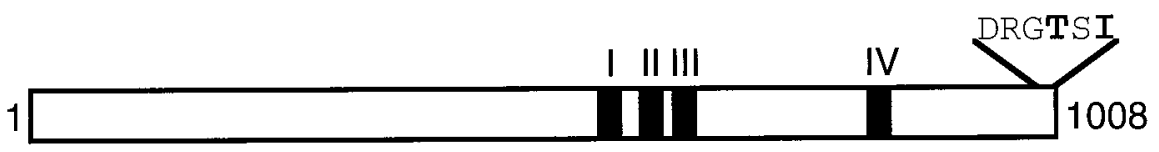

Gal 4 activation hybrid

PSD-93 (83-421)

PSD-93 (83-421)

PSD-93 (83-421)

PSD-93 (83-421)

PSD-93 (83-421)
PSD-93 (83-421) $\beta$ Gal activation

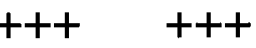

-

$-$

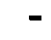

$+t+\quad+t$

$-$

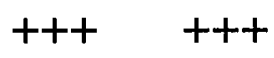

PSD-93 (83-421)
His 3 activation
A
Gal 4 DNA binding hybrid

$\delta 2$ C-terminus (amino acids 852-1008)

$\delta 2$ C-terminus (852-1008)

$\delta 2$ C-terminus (852-1008)

$\delta 2$ C-terminus (852-1008)

82 C-terminus (852-1008)

$\delta 2$ C-terminus (852-1008)
Gal 4 activation hybrid
His 3 activation activation
Figure 3. Interaction of the $\delta 2 \mathrm{C}$ terminus with the PDZ domains of PSD-95. A, Yeast HF7c cells were cotransformed with expression vectors encoding the $\delta 2$ WT C terminus-GAL 4 DNA binding domain fusion protein and various GAL 4 activation domain fusion proteins. Each transformation mixture was plated on synthetic dextrose plates lacking tryptophan and leucine. Interaction was measured by the filter assay (Clontech) as described previouly (Fields and Song, 1989) and by growth on histidine-deficient media. Data are representative of experiments repeated three times with similar results. $B$, A schematic illustrating the conserved domains of the PSD-95 family of proteins.
PSD-95 PDZ1 (40-124)

PSD-95 PDZ2 (158-314)

PSD-95 PDZ3 (311-384)

PSD-95 PDZ1-2 (40-314)

$+++$

PSD-95 PDZ2-3 (158-384)

$++$

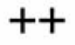

PSD-95 PDZ1-3 (40-384)

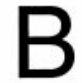

1 PDZ1 

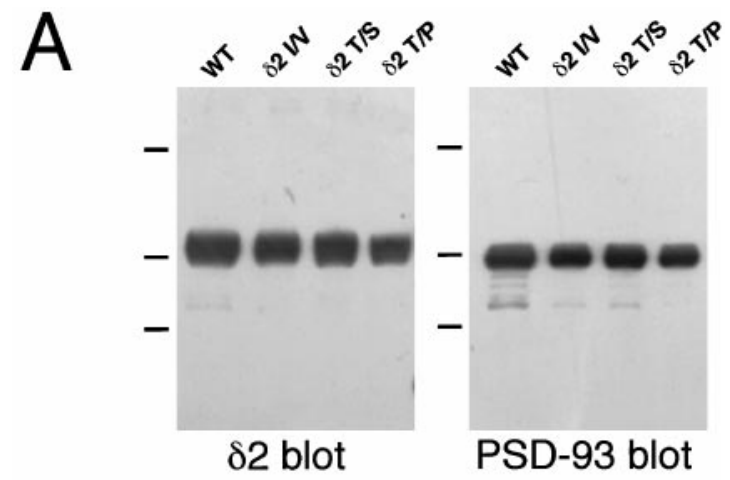

B

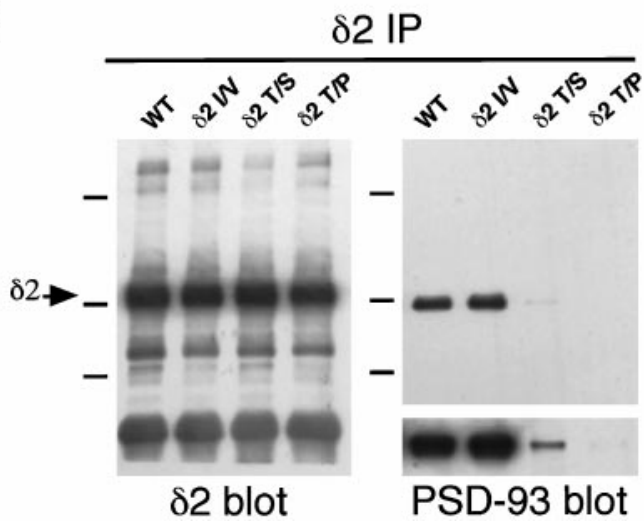

Figure 4. PSD-93 specifically associates with $\delta 2$ in heterologous cells. HEK-293 cells were transiently transfected with PSD-93 and $\delta 2 \mathrm{WT}, \delta 2 \mathrm{I}$ $1008 \mathrm{~V}, \delta 2 \mathrm{~T} 1006 \mathrm{~S}$, or $\delta 2 \mathrm{~T} 1006 \mathrm{P}$. Cells were solubilized in $1 \%$ Triton $\mathrm{X}-100$, and $\delta 2$ was immunoprecipitated with $\delta 2$ polyclonal antibodies. $A$, Total protein homogenate was resolved by SDS-PAGE and then immunoblotted with $\delta 2$ (left) or PSD-93 (right) antibodies. $B, \delta 2$ immunoprecipitated samples were resolved by SDS-PAGE and immunoblotted with either $\delta 2$ (left) or PSD-93 (right) antibodies. Overexposure of the PSD-93 blot is included as an inset of the right panel to illustrate the small amount of PSD-93 that coimmunoprecipitates with the $\delta 2 \mathrm{~T} 1006 \mathrm{~S}$ point mutant. Prestained molecular weight markers are indicated with bars corresponding to myosin, phosphorylase B, and bovine serum albumin $\left(M_{\mathrm{r}}\right.$ of 210 , 103 , and $71 \mathrm{kDa}$, respectively). In $B$, the band corresponding to $\delta 2$ is indicated with an arrow. The additional background bands result from identical antibodies being used for both the immunoprecipitation and immunoblot.

dithiobis(succinimidylpropionate) (DSP) (Pierce) following a modification of a previously described method (Wenthold et al., 1992). DSP, which has a spacer arm length of $12 \AA$, cross-links primary amines and contains a disulfide bond that can be cleaved by reducing agents. Frozen cerebella were homogenized with a Polytron in 50 mM HEPES, pH 7.5, and centrifuged at $100,000 \times g$ for $30 \mathrm{~min}$. The membrane fraction was resuspended in $50 \mathrm{mM}$ HEPES, pH 7.5, and centrifuged again. The pellet was resuspended by sonication in $50 \mathrm{~mm}$ HEPES, $\mathrm{pH} 7.5$, at a protein concentration estimated at $6 \mathrm{mg} / \mathrm{ml}$. DSP was prepared in DMSO at 20 $\mathrm{mg} / \mathrm{ml}$. It was added to the cerebellar membranes to final concentrations of 0,200 , and $2000 \mu \mathrm{M}$, and the samples were incubated with mixing for $30 \mathrm{~min}$ at $4^{\circ} \mathrm{C}$. Glycine was then added to a final concentration of $150 \mathrm{~mm}$, and the membranes were diluted with $50 \mathrm{~mm}$ Tris- $\mathrm{HCl}, \mathrm{pH} \mathrm{7.5}$, and centrifuged at $100,000 \times g$ for $20 \mathrm{~min}$. The pellet was resuspended in 50 $\mathrm{mm}$ Tris $\mathrm{HCl}, \mathrm{pH} 7.5$, SDS was added to a final concentration of $1 \% \mathrm{w} / \mathrm{v}$, and the samples were incubated at $37^{\circ} \mathrm{C}$ for $30 \mathrm{~min}$. Triton $\mathrm{X}-100$ was added to a final concentration of $2 \% \mathrm{w} / \mathrm{v}$, and the samples were centrifuged at $100,000 \times g$ for $20 \mathrm{~min}$. The supernatants were used for immunoprecipitation. Antibodies to $\delta 1 / 2(10 \mu \mathrm{g})$ or PSD-93/95 $(2.5 \mu \mathrm{l})$ were attached to protein A agarose $(25 \mu \mathrm{l}$ of packed resin), and the cross-linked supernatants were incubated for $2 \mathrm{hr}$ at $4^{\circ} \mathrm{C}$. After washing the resin with $50 \mathrm{~mm}$ Tris- $\mathrm{HCl}$ containing $0.1 \%$ Triton $\mathrm{X}-100$, the bound protein was extracted from the resin by boiling in sample buffer containing $5 \% \beta$-mercaptoethanol for $3 \mathrm{~min}$.
EM analysis. The postembedding immunogold method has been described previously (Wang et al., 1998) and is modified from the method of Matsubara et al. (1996). Briefly, a male Sprague Dawley rat was perfused with $4 \%$ paraformaldehyde plus $0.5 \%$ glutaraldehyde in $0.1 \mathrm{M}$ phosphate buffer. Two hundred micrometer parasagittal sections of the rostral cerebellum (folia III-V) were cryoprotected in $30 \%$ glycerol and frozen in liquid propane in a Leica (Vienna, Austria) EM CPC. Frozen sections were immersed in $1.5 \%$ uranyl acetate in methanol at $-90^{\circ} \mathrm{C}$ in a Leica AFS freeze-substitution instrument, infiltrated with Lowicryl HM 20 resin at $-45^{\circ} \mathrm{C}$, and polymerized with UV light. Thin sections were incubated in $0.1 \%$ sodium borohydride plus $50 \mathrm{~mm}$ glycine in Tris-buffered saline- $0.1 \%$ Triton X-100 (TBST), followed by $10 \%$ NGS in TBST, primary antibody in 1\% NGS-TBST, $10 \mathrm{~nm}$ immunogold (Goldmark Biologicals, Phillipsburg, NJ) in 1\% NGS-TBST plus $0.5 \%$ polyethylene glycol, and finally staining in uranyl acetate and lead citrate. For double labeling, two primary antibodies were combined and two immunogolds were combined (10 nm goat anti-guinea pig and $30 \mathrm{~nm}$ goat anti-rabbit; Goldmark Biologicals). Primary antibodies were used at dilutions of 1:100 for PSD-93 and 1:50 for $\delta 1 / 2$ (rabbit polyclonal).

\section{RESULTS}

To identify proteins that interact with $\delta 2$ receptors, we screened a yeast two-hybrid rat brain cDNA library (Clontech) with the C-terminal cytosolic domain of $\delta 2$ (amino acids 852-1008). We screened $\sim 1.94$ million clones and identified five clones that activated transcription of the HIS 3 and $\beta$-galactosidase reporter genes. Of these five positives, one was SAP-97 (amino acids 130-662) (Müller et al., 1995), and four encoded a novel protein. The last six amino acids of $\delta 2$ are DRGTSI (single letter amino acid code), a sequence that is similar to the well characterized $\mathrm{T} / \mathrm{SxV}$ motif contained in NMDA receptor subunits and Shaker $\mathrm{K}^{+}$channels (Fig. 1) known to interact with the PSD-95 family of proteins. This suggested that $\delta 2$ might also interact with members of the PSD-95 family of proteins. Using the yeast two-hybrid system, we found that truncation of the terminal six amino acids of $\delta 2$ disrupts the interaction of $\delta 2$ and SAP-97 (data not shown). We also determined that $\delta 2$ interacts with PSD-93 and PSD-95 (Figs. $2 A, 3 A$ ), in addition to SAP-97. $\delta 2$ is specifically localized to cerebellar Purkinje cells (Araki et al., 1993; Mayat et al., 1995; Zhao et al., 1997), which express little or no SAP-97 or PSD-95 (Kim et al., 1996). In contrast, PSD-93 is expressed in Purkinje cells (Brenman et al., 1996b; Kim et al., 1996), making it an excellent candidate to interact with $\delta 2$ in vivo. Therefore, we used PSD-93 in most of the experiments to characterize the interaction with $\delta 2$.

Using the yeast two-hybrid system, we analyzed the sequence determinants of $\delta 2$ necessary for interaction with PSD-93 and determined whether $\delta 1$ interacts with PSD-93 as well. The C termini of both $\delta 1$ and $\delta 2$ interact with PSD-93, and truncation of the last six amino acids of $\delta 2$ disrupts the interaction (Fig. $2 A$ ). The final amino acid and the amino acid at the -2 position have been shown to be important for binding to MAGUKs (Sheng and Kim, 1996; Ziff, 1997; Craven and Bredt, 1998). Figure 2B is a schematic of $\delta 2$, indicating the last six amino acids containing the conserved motif and the critical amino acids in the 0 and -2 positions. Mutation of threonine (T) 1006 to proline (P) or mutation of isoleucine (I) 1008 to alanine (A) disrupts the interaction with PSD-93 (Fig. $2 A$ ). In contrast, changing the terminal isoleucine (1008) to valine (V) has no effect on binding. Interestingly, the mutation of threonine 1006 to serine (S), a conservative substitution, completely disrupts the interaction with PSD-93. Thus, the sequence determinants for the $\delta 2$ interaction with PSD-93 differ from those of Shaker $\mathrm{K}^{+}$channel interactions with PSD-95 and PSD-93 (Kim et al., 1995; Kim and Sheng, 1996).

We also characterized the specificity of the $\delta 2$ interaction with 

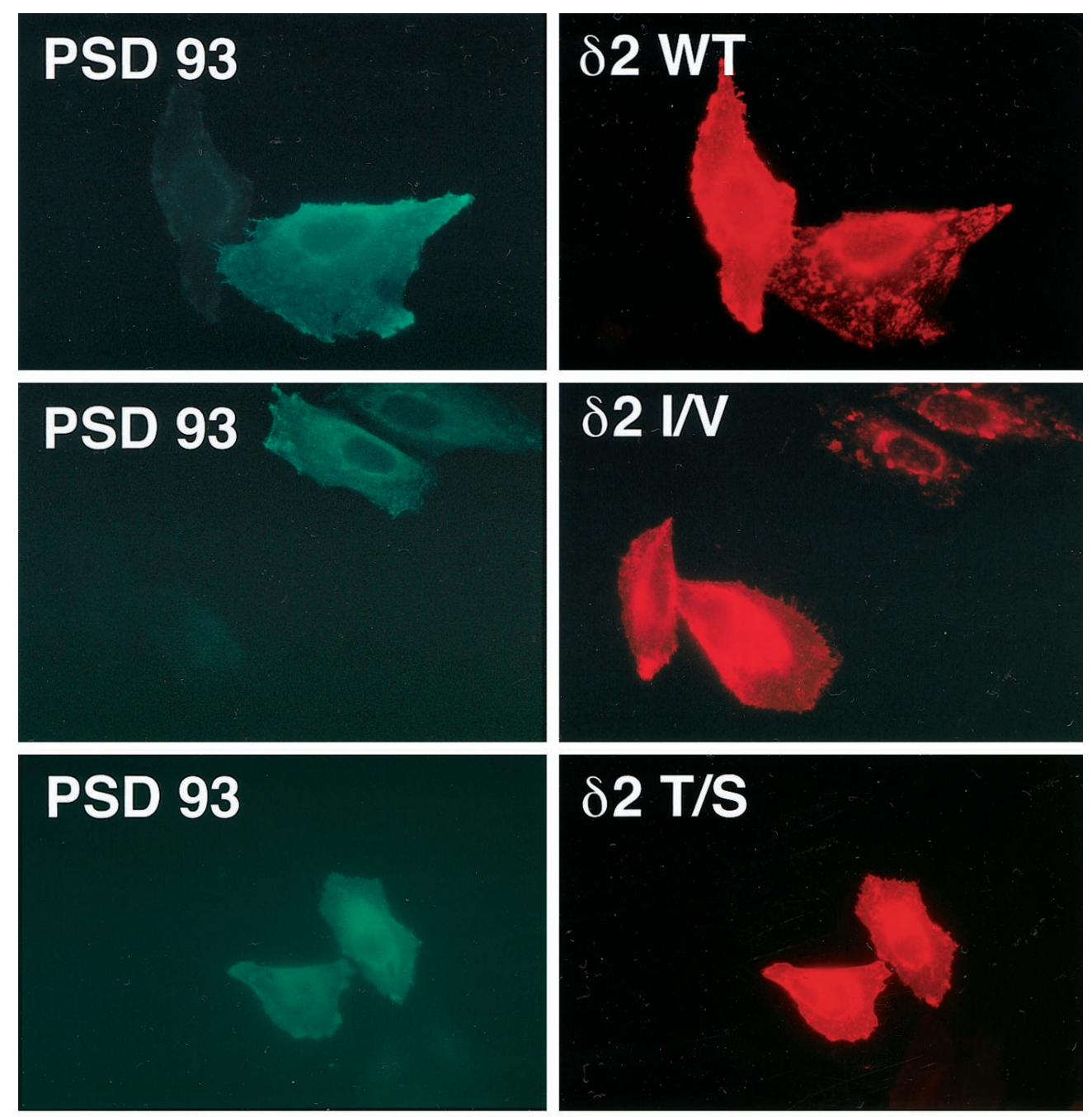

Figure 5. Clustering of $\delta 2$ after coexpression with PSD-93. HeLa cells were transiently transfected with PSD-93 and $\delta 2 \mathrm{WT}, \delta 2 \mathrm{I} 1008 \mathrm{~V}, \delta 2 \mathrm{~T} 1006 \mathrm{~S}$, or $\delta 2 \mathrm{~T}$ 1006 P. Cells were fixed, permeabilized, and incubated with PSD-93/95 monoclonal antibodies and $\delta 2$ polyclonal antibodies. Immunoreactivity was visualized using a combination of FITC-conjugated anti-mouse secondary antibodies and rhodamine-conjugated anti-rabbit secondary antibodies. All micrographs were taken using a $63 \times$ objective.
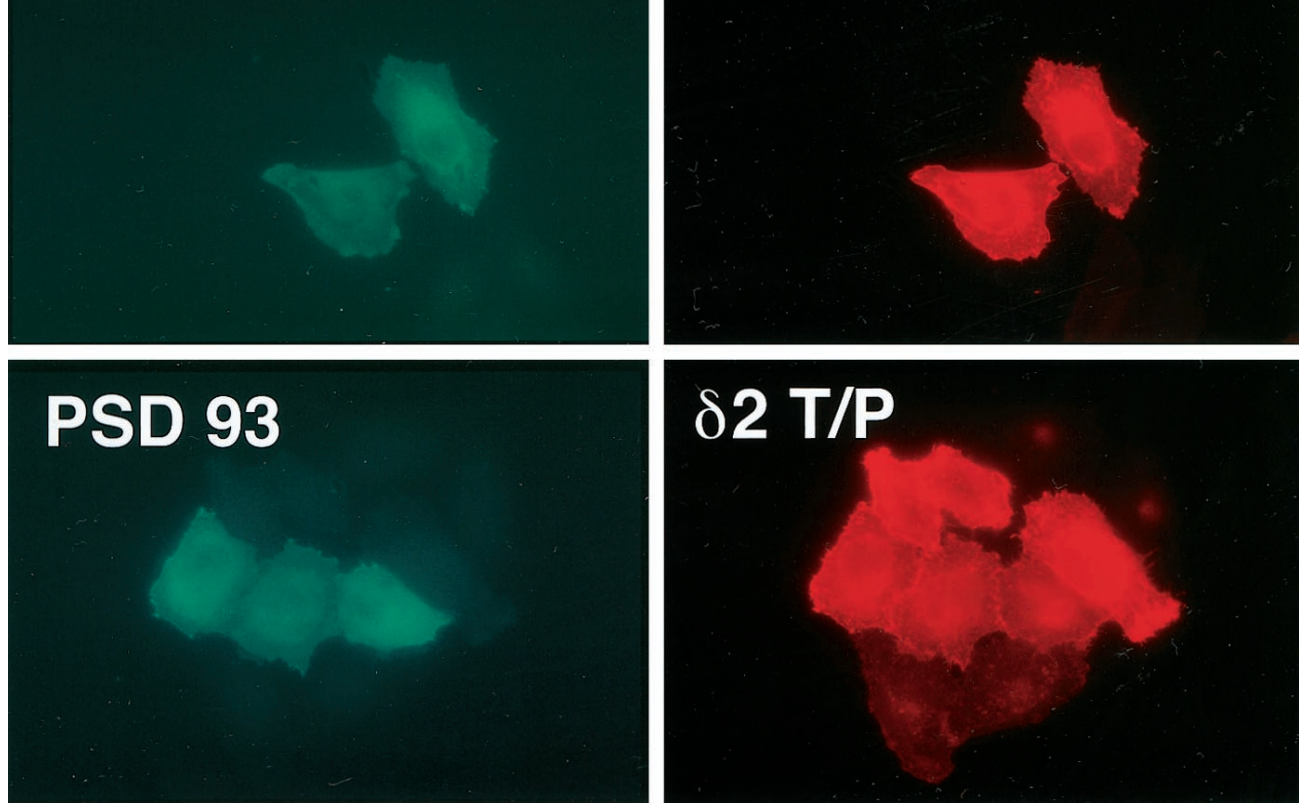

various combinations of the three PDZ domains of PSD-95 (Fig. $3 A$ ), which are highly conserved between members of the PSD-95 family of proteins (Fig. $3 B$ ). $\delta 2$ displayed a robust interaction with PDZ 1-3 or PDZ 1-2, whereas it interacted to a lesser extent with PDZ 2-3, and the binding was diminished further when coexpressed with PDZ 2 alone. $\delta 2$ did not interact with PDZ 1 or PDZ 3 alone. Thus, $\delta 2$ interacted with PDZ 2 and not PDZ 1 or PDZ 3 , yet strongly preferred PDZ 1 and 2 together. This is similar to the binding preferences described for the interaction of certain $\mathrm{K}^{+}$channels with PSD-95 (Kim et al., 1995).

We next asked whether full-length $\delta 2$ interacts with PSD-93 when the two proteins are coexpressed in heterologous cells. Using a coimmunoprecipitation assay, we found that the two proteins bound robustly when coexpressed in HEK-293 cells (Fig. 4). As detected by yeast two-hybrid, we found that $\delta 2$ containing a conservative I $1008 \mathrm{~V}$ mutation retained binding to PSD-93, whereas mutating the T $1006 \mathrm{P}$ disrupted binding to PSD-93. The conservative $\mathrm{T} 1006 \mathrm{~S}$ mutation almost completely disrupted the binding of $\delta 2$ and PSD-93, as was the case using the yeast two-hybrid assay, although there was some residual binding above background (Fig. 4, inset).

The PSD-95 family of proteins has been reported to mediate clustering of receptors at synapses, as well as in heterologous cells (Kim et al., 1995, 1996; Kim and Sheng, 1996; Tejedor et al., 1997). To determine whether PSD-93 clusters $\delta 2$, we coexpressed PSD-93 and $\delta 2$ in HeLa cells and analyzed the distribution of the 
proteins using immunofluorescence. Coexpression of PSD-93 with $\delta 2$ resulted in a patchy redistribution of $\delta 2$ in HeLa cells, which contrasts dramatically with the diffuse homogenous distribution of $\delta 2$ seen in cells expressing $\delta 2$ alone (Fig. 5). To confirm the specificity of the clustering, we also cotransfected PSD-93 with several $\delta 2$ mutants. We found that $\delta 2$ I $1008 \mathrm{~V}$ also clustered when coexpressed with PSD-93. In contrast, when either $\delta 2 \mathrm{~T}$ $1006 \mathrm{~S}$ or $\delta 2 \mathrm{~T} 1006 \mathrm{P}$ were coexpressed with PSD-93, they maintained the diffuse distribution observed when $\delta 2$ was expressed alone. We could not analyze the clustering of the $\delta 2$ I 1008 A mutant because this mutation eliminated recognition of the protein by the $\delta 1 / 2$ antibodies, which were raised against the extreme $\mathrm{C}$ terminus. Thus, the clustering of $\delta 2$ in heterologous cells is dependent on a direct interaction of $\delta 2$ with PSD-93. Accordingly, $\delta 2$ mutations that disrupt the clustering activity of PSD-93 are mutations that disrupt the direct interaction of $\delta 2$ with PSD-93 in the yeast two-hybrid assay (Fig. $2 A$ ) and in the coimmunoprecipitation assay (Fig. 4).

We performed coimmunoprecipitation experiments from adult rat cerebellum to determine whether endogenous $\delta 2$ and PSD-93 interact in brain. We found that PSD-93 does coimmunoprecipitate with $\delta 2$ from cerebellum (Fig. 6) and vice versa (data not shown). Interestingly, robust binding of the two proteins is dependent on the detergent, which is used to solubilize the membranes. Although Triton X-100 solubilizes a large amount of PSD-93 and $\delta 2$ from cerebellar extracts and it has been shown previously that $\delta 2$ can be immunoprecipitated after Triton X-100 solubilization (Mayat et al., 1995), the two do not coimmunoprecipitate, whereas $\delta 2$ and PSD-93 coimmunoprecipitate well using DOC-solubilized tissue. This is in sharp contrast to the efficient $\delta 2$ and PSD-93 coimmunoprecipitation using Triton X-100 when the two proteins are coexpressed in heterologous cells (Fig. 4). Failure of $\delta 2$ and PSD-93 to coimmunoprecipitate from Triton X-100-solubilized cerebellar extracts may indicate that these proteins only interact at postsynaptic densities in brain, which are not soluble in Triton X-100 (Cho et al., 1992).

To address the possibility that the coimmunoprecipitation of $\delta 2$ and PSD-93 is caused by an interaction between the two proteins that forms after detergent solubilization rather than indicating an interaction that is present under normal conditions, we crosslinked cerebellar membranes before detergent solubilization using the covalent cross-linker DSP. After cross-linking, the membranes were solubilized with SDS, neutralized with Triton X-100, and immunoprecipitated with antibodies to $\delta 2$ and PSD-93. As shown in Figure 7, $\delta 2$ coimmunoprecipitates with PSD-93 after cross-linking with $200 \mu \mathrm{M}$ DSP. Coimmunoprecipitation is not seen in the uncross-linked sample or when cross-linking is done with $2000 \mu \mathrm{M}$ DSP. At the higher concentration of cross-linker, essentially all of the PSD-93/95 is insoluble, as determined by analyzing the SDS-soluble fraction after cross-linking. A significant amount of the $\delta 2$ remains soluble, and this may reflect the cytoplasmic pool of receptor, which is commonly observed for glutamate receptors. GluR2/3 is not cross-linked to PSD$93 / 95$ under these conditions. $\delta 2$ was less effective in coimmunoprecipitating PSD-93, although a small amount of coimmunoprecipitation was seen after cross-linking with $200 \mu \mathrm{M}$ DSP (data not shown). We attribute this to the fact that the $\delta 2$ antibody is made to the $\mathrm{C}$ terminus, the same region involved in the interaction with PSD-93, and the epitope may not be readily available after cross-linking. However, a significant amount of $\delta 2$ was immunoprecipitated, reflecting an uncross-

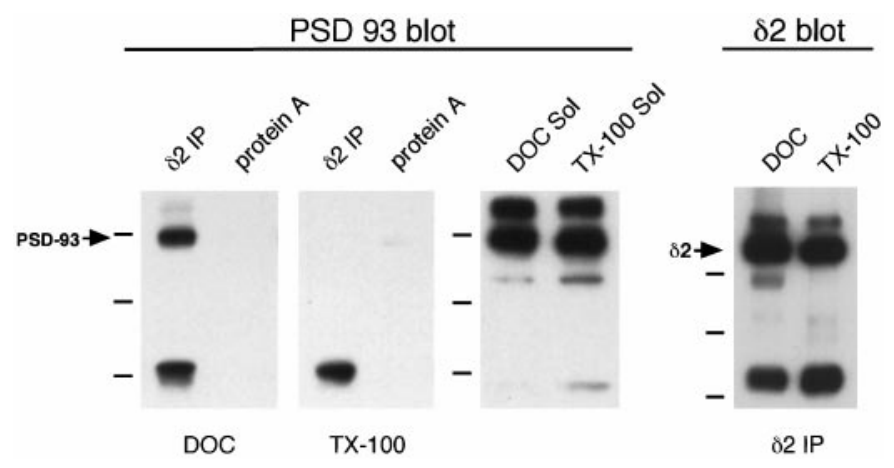

Figure 6. PSD-93 and $\delta 2$ interact in rat brain cerebellum. Frozen rat cerebella were solubilized in $1 \%$ DOC or $1 \%$ Triton X-100, and $\delta 2$ was immunoprecipitated using $\delta 2$ antibodies. Total soluble protein and immunoprecipitates were resolved by SDS-PAGE and probed with either PSD-93 or $\delta 2$ antibodies. Prestained molecular weight markers are indicated with bars corresponding to phosphorylase B, bovine serum albumin, and ovalbumin $\left(M_{\mathrm{r}}\right.$ of 103,71 , and $46 \mathrm{kDa}$, respectively).
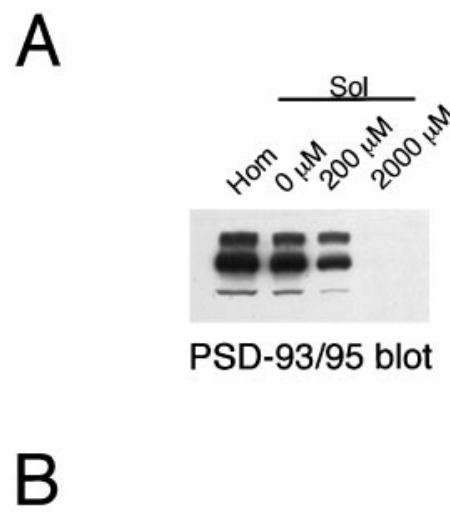

PSD-93/95 blot

$B$

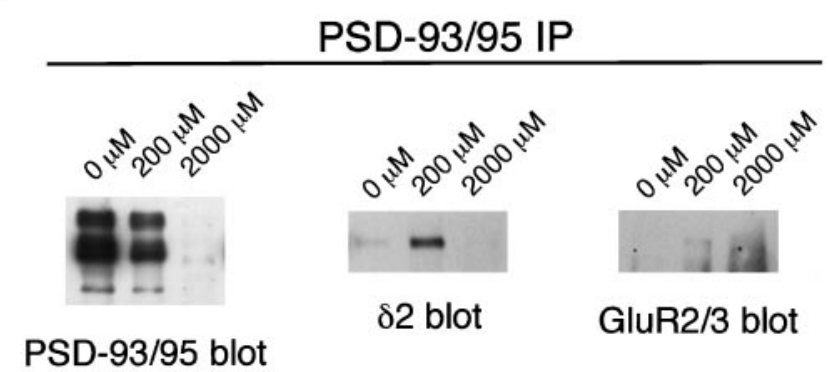

Figure 7. Chemical cross-linking of PSD-93 and $\delta 2$ in rat brain cerebellum. Cerebellar membranes were cross-linked with DSP following a modification of a previously described method (Wenthold et al., 1992; see Materials and Methods). DSP (0, 200, or $2000 \mu \mathrm{M})$ was used as indicated. After cross-linking, the membranes were solubilized in SDS, followed by Triton X-100, and in total homogenates or soluble fractions $(A)$, resolved by SDS-PAGE, and immunoblotted with the antibodies indicated. $B$, PSD 93/95 was immunoprecipitated from the soluble fraction, resolved by SDS-PAGE, and immunoblotted with the antibodies indicated. The GluR2/3 immunoblot was overexposed compared with the PSD-93/95 and $\delta 2$ blot to reveal even low levels of cross-linking.

linked pool, indicating that the cross-linking did not affect the $\mathrm{C}$ terminus of $\delta 2$ in a nonspecific way.

Finally, we characterized the subcellular localization of PSD-93 and $\delta 2$ using immunoelectron microscopy. In sections of the molecular layer of the cerebellum, immunogold labeling with a PSD-93 antibody was associated most commonly with the postsynaptic membrane in Purkinje cell parallel and climbing 

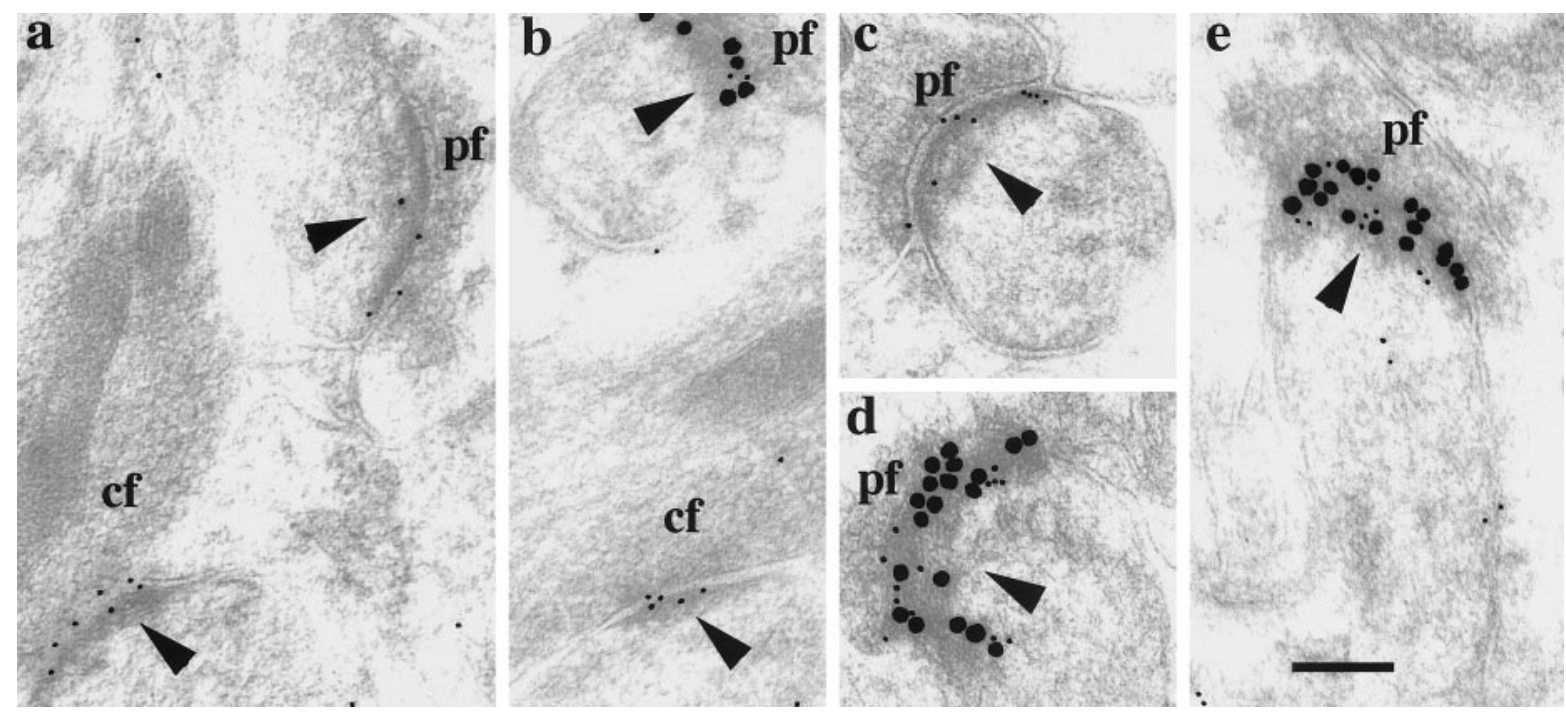

Figure 8. Colocalization of PSD-93 and $\delta 2$ at parallel fiber synapses. Sections were single-labeled with PSD-93 antibody (from guinea pig; 10 nm gold) in $a$ and $c$ and were double-labeled with PSD-93 antibody (10 nm gold) and $\delta 21 / 2$ antibody ( $30 \mathrm{~nm}$ gold) in $b, d$, and $e$. PSD-93 antibody labels both parallel ( $p f)$ and climbing ( $c f)$ fiber synapses (arrowheads), whereas $\delta$ antibody labels only parallel fiber synapses. Scale bar, $0.2 \mu \mathrm{m}$.

fiber synapses (Fig. 8). In sections labeled with both PSD-93 and $\delta 1 / 2$ antibodies, parallel fiber synapses showed labeling for both antibodies interspersed along the postsynaptic membrane. In contrast, climbing fiber synapses usually showed labeling only for PSD-93. Labeling for PSD-93 in climbing fiber and parallel fiber synapses was confirmed using preembedding immunoperoxidase with the same antibody and using post-embedding immunogold with a second PSD-93 antibody, which was made to a different region of the protein (data not shown).

\section{DISCUSSION}

Recent work has demonstrated that several PDZ domaincontaining proteins interact with the $\mathrm{C}$ termini of glutamate receptors. In addition to the PSD-95 family of proteins that bind to NMDA receptors, AMPA receptors have been shown to interact with glutamate receptor-interacting protein (GRIP) (Dong et al., 1997) and AMPA-binding protein (ABP) (Srivastava et al., 1998), which have multiple PDZ domains. Thus, it has been proposed that different subclasses of glutamate receptors interact specifically with distinct PDZ domain-containing proteins. So far, the only exception to this specificity is a recent report in which the AMPA receptor subunit GluR1 was shown to interact with SAP-97 (Leonard et al., 1998). This finding is unique in that GluR1 specifically interacted with SAP-97 and not the other members of the PSD-95 family.

In the present study, we have demonstrated that the PSD-95 family of proteins interacts with $\delta$ receptors, in addition to NMDA receptors. We have specifically shown that $\delta 2$ interacts with PSD-93 using the yeast two-hybrid system and that the two proteins coimmunoprecipitate when coexpressed in heterologous cells. We confirmed that this interaction also occurs in vivo by coimmunoprecipitating PSD-93 and $\delta 2$ from adult rat cerebella and by cross-linking analysis. The interaction of these two proteins depends on the final six amino acids of $\delta 2$ (DRGTSI; single letter amino acid code), which generally conform to the $\mathrm{T} / \mathrm{SxV}$ motif found at the $\mathrm{C}$ termini of both Shaker $\mathrm{K}^{+}$channels and NMDAR2 subunits. The $\delta$ receptors have a terminal isoleucine instead of the terminal valine described for Shaker $\mathrm{K}^{+}$channels and NMDA receptors. Thus, they share the T/SxI motif with the inwardly rectifying $\mathrm{K}^{+}$channel Kir 2.3 , which also binds to the PSD-95 family of proteins (Cohen et al., 1996) (Fig. 1). The $\delta 2$ interaction with PSD-93 is strongly dependent on $\mathrm{T}$ at the -2 position, which differs from NMDA Shaker $\mathrm{K}^{+}$channels which prefer either $\mathrm{T}$ or $\mathrm{S}$ in this position. This suggests that the surrounding amino acids play a greater role in the interaction than previously recognized. Recently, a similar observation was made by Niethammer et al. (1998).

We also demonstrated that PSD-93 induces the clustering of $\delta 2$ in heterologous cells. Thus, PSD-93 can redistribute surface $\delta 2$ receptors, just as other members of the PSD-95 family of proteins can cluster NMDA receptors and Shaker $\mathrm{K}^{+}$channels. Because we also demonstrated that PSD-93 binds to $\delta 2$ in the cerebellum and that these two proteins colocalize at parallel fiber synapses on Purkinje cells, it is likely that PSD-93 plays a role in localization of $\delta 2$ at synapses. In addition to the proposed role in the docking of $\delta 2$ receptors, it is also possible that PSD-93 links $\delta 2$ to multiprotein complexes involved in intracellular signaling via interactions with proteins such as neuronal nitric oxide synthase (Brenman et al., 1996a) and synGAP (Chen et al., 1998; Kim et al., 1998).

Although the expression of $\delta 2$ is highest in Purkinje neurons, $\delta 1$ and/or $\delta 2$ are expressed elsewhere in the brain (Lomeli et al., 1993; Mayat et al., 1995; Petralia et al., 1996). Because both $\delta$ and NMDA receptors bind to the PSD-95 family of proteins, it is possible that the two receptors compete for the same synaptic anchors. Interestingly, the developmental profile of functional NMDA receptors in Purkinje cells would support this idea. Functional NMDA receptors are observed only on young Purkinje cells (Crepel and Krupa, 1990; Rosenmund et al., 1992), although expression of both NR1 and NR2 subunits is seen in adult and developing animals (Akazawa et al., 1994). The dramatic increase in $\delta 2$ expression beginning at postnatal day 10 approximately coincides with the decrease in functional NMDA receptors. If this is the case, then animals lacking $\delta 2$ should express functional NMDA receptors as adults. A competition for synaptic anchors may provide yet another mechanism for regulating the expression of functional receptors. 
Although there is growing evidence that the PSD-95 family of proteins is involved in anchoring receptors at synapses, there is little insight into whether or not the presence of the anchor alone is sufficient to determine the expression of the receptor. It has been shown that synaptic clusters of NMDA receptors on cultured hippocampal neurons are always associated with, and preceeded by, clusters of PSD-95 (Rao et al., 1998). If PSD-95 expression mediates clustering of receptors at specific synapses, then all synapses that contain the appropriate anchor would also contain the receptor. In the Purkinje cell, we find that both climbing fiber and parallel fiber synapses express PSD-93, but only parallel fiber synapses express $\delta 2$ receptors. This suggests that additional factors play a role in determining the synapsespecific expression of glutamate receptors. One possibility is that receptors are selectively targeted to a synapse and the anchoring proteins dock the receptors in a nonselective manner. In this case, a separate mechanism is required for selectively guiding intracellular organelles with certain cargo to appropriate synapses. A second possibility is that the receptor-anchor interaction is actively regulated. If this is true, then receptors may be targeted to multiple synapses in a single neuron but only selectively retained at the proper sites. In this case, a number of other proteins may be involved in determining both the number of anchors occupied and the nature of the receptors that occupy them. Either scenario is consistent with the fact that PSD-93 and other family members bind to proteins as divergent as NMDA, $\delta$, and AMPA receptors, as well as $\mathrm{K}^{+}$channels, which are often expressed in the same neurons.

\section{REFERENCES}

Akazawa C, Shigemoto R, Bessho Y, Nakanishi S, Mizuno N (1994) Differential expression of five $N$-methyl-D-aspartate receptor subunit mRNAs in the cerebellum of developing and adult rats. J Comp Neurol 347:150-160.

Araki K, Meguro H, Kushiya E, Takayama C, Inoue Y, Mishina M (1993) Selective expression of the glutamate receptor channel $\delta 2$ subunit in cerebellar Purkinje cells. Biochem Biophys Res Commun 197:1267-1276.

Blackstone CD, Moss SJ, Martin LJ, Levey AI, Price DL, Huganir RL (1992) Biochemical characterization and localization of a non- $N$ methyl-D-aspartate glutamate receptor in rat brain. J Neurochem 58:1118-1126.

Brenman JE, Chao DS, Gee SH, McGee AW, Craven SE, Santillano DR, Wu Z, Huang F, Xia H, Peters MF, Froehner SC, Bredt DS (1996a) Interaction of nitric oxide synthase with the postsynaptic density protein PSD-95 and $\alpha 1$-syntrophin mediated by PDZ domains. Cell 84:757-767.

Brenman JE, Christopherson KS, Craven SE, McGee AW, Bredt DS (1996b) Cloning and characterization of postsynaptic density 93, a nitric oxide synthase interacting protein. J Neurosci 16:7407-7415.

Chen HJ, Rojas-Soto M, Oguni A, Kennedy MB (1998) A synaptic Ras-GTPase activating protein (p135 SynGAP) inhibited by CaM kinase II. Neuron 20:895-904.

Cho KO, Hunt CA, Kennedy MB (1992) The rat brain postsynaptic density fraction contains a homolog of the Drosophila discs-large tumor suppressor protein. Neuron 9:929-942.

Cohen NA, Brenman JE, Snyder SH, Bredt DS (1996) Binding of the inward rectifier $\mathrm{K}^{+}$channel Kir 2.3 to PSD-95 is regulated by protein kinase A phosphorylation. Neuron 17:759-767.

Craven SE, Bredt DS (1998) PDZ proteins organize synaptic signaling pathways. Cell 93:495-498.

Crepel F, Krupa M (1990) Modulation of the responsiveness of cerebellar Purkinje cells to excitatory amino acids. Adv Exp Med Biol 268:323-329.
Dong H, O'Brien RJ, Fung ET, Lanahan AA, Worley PF, Huganir RL (1997) GRIP: a synaptic PDZ domain-containing protein that interacts with AMPA receptors. Nature 386:279-284.

Fields S, Song O (1989) A novel genetic system to detect protein-protein interactions. Nature 340:245-246.

Hirano T, Kasono K, Araki K, Mishina M (1995) Suppression of LTD in cultured Purkinje cells deficient in the glutamate receptor $\delta 2$ subunit. NeuroReport 6:524-526.

Hollmann M, Heinemann S (1994) Cloned glutamate receptors. Annu Rev Neurosci 17:31-108.

Jeromin A, Huganir RL, Linden DJ (1996) Suppression of the glutamate receptor $\delta 2$ subunit produces a specific impairment in cerebellar longterm depression. J Neurophysiol 76:3578-3583.

Kashiwabuchi N, Ikeda K, Araki K, Hirano T, Shibuki K, Takayama C, Inoue Y, Kutsuwada T, Yagi T, Kang Y (1995) Impairment of motor coordination, Purkinje cell synapse formation, and cerebellar long-term depression in GluR $\delta 2$ mutant mice. Cell 81:245-252.

Kim E, Sheng M (1996) Differential $\mathrm{K}^{+}$channel clustering activity of PSD-95 and SAP97, two related membrane-associated putative guanylate kinases. Neuropharmacology 35:993-1000.

Kim E, Niethammer M, Rothschild A, Jan YN, Sheng M (1995) Clustering of Shaker-type $\mathrm{K}^{+}$channels by interaction with a family of membrane-associated guanylate kinases. Nature 378:85-88.

Kim E, Cho KO, Rothschild A, Sheng M (1996) Heteromultimerization and NMDA receptor-clustering activity of Chapsyn-110, a member of the PSD-95 family of proteins. Neuron 17:103-113.

Kim JH, Liao D, Lau LF, Huganir RL (1998) SynGAP: a synaptic RasGAP that associates with the PSD-95/SAP90 protein family. Neuron 20:683-691.

Kornau HC, Schenker LT, Kennedy MB, Seeburg PH (1995) Domain interaction between NMDA receptor subunits and the postsynaptic density protein PSD-95. Science 269:1737-1740.

Landsend AS, Amiry-Moghaddam M, Matsubara A, Bergersen L, Usami S, Wenthold RJ, Ottersen OP (1997) Differential localization of $\delta$ glutamate receptors in the rat cerebellum: coexpression with AMPA receptors in parallel fiber-spine synapses and absence from climbing fiber-spine synapses. J Neurosci 17:834-842.

Leonard AS, Davare MA, Horne MC, Garner CC, Hell JW (1998) SAP97 is associated with the $\alpha$-amino-3-hydroxy-5-methylisoxazole-4propionic acid receptor GluR1 subunit. J Biol Chem 273:19518-19524.

Lomeli H, Sprengel R, Laurie DJ, Köhr G, Herb A, Seeburg PH, Wisden W (1993) The rat $\delta-1$ and $\delta$-2 subunits extend the excitatory amino acid receptor family. FEBS Lett 315:318-322.

Matsubara A, Laake JH, Davanger S, Usami S, Ottersen OP (1996) Organization of AMPA receptor subunits at a glutamate synapse: a quantitative immunogold analysis of hair cell synapses in the rat organ of Corti. J Neurosci 16:4457-4467.

Mayat E, Petralia RS, Wang YX, Wenthold RJ (1995) Immunoprecipitation, immunoblotting, and immunocytochemistry studies suggest that glutamate receptor $\delta$ subunits form novel postsynaptic receptor complexes. J Neurosci 15:2533-2546.

Müller BM, Kistner U, Veh RW, Cases-Langhoff C, Becker B, Gundelfinger ED, Garner CC (1995) Molecular characterization and spatial distribution of SAP97, a novel presynaptic protein homologous to SAP90 and the Drosophila discs-large tumor suppressor protein. J Neurosci 15:2354-2366.

Niethammer M, Valtschanoff JG, Kapoor TM, Allison DW, Weinberg TM, Craig AM, Sheng M (1998) CRIPT, a novel postsynaptic protein that binds to the third PDZ domain of PSD-95/SAP90. Neuron 20:693-707.

Petralia RS, Wang YX, Zhao HM, Wenthold RJ (1996) Ionotropic and metabotropic glutamate receptors show unique postsynaptic, presynaptic, and glial localizations in the dorsal cochlear nucleus. J Comp Neurol 372:356-383.

Rao A, Kim E, Sheng M, Craig AM (1998) Heterogeneity in the molecular composition of excitatory postsynaptic sites during development of hippocampal neurons in culture. J Neurosci 18:1217-1229.

Rosenmund C, Legendre P, Westbrook GL (1992) Expression of NMDA channels on cerebellar Purkinje cells acutely dissociated from newborn rats. J Neurophysiol 68:1901-1905.

Sheng M, Kim E (1996) Ion channel associated proteins. Curr Opin Neurobiol 6:602-608.

Srivastava S, Osten P, Vilim FS, Khatri L, Inman G, States B, Daly C, DeSouza S, Abagyan R, Valtschanoff JG, Weinberg RJ, Ziff EB (1998) 
Novel anchorage of GluR2/3 to the postsynaptic density by the AMPA receptor-binding protein ABP. Neuron 21:581-591.

Tejedor FJ, Bokhari A, Rogero O, Gorczyca M, Zhang J, Kim E, Sheng M, Budnik V (1997) Essential role for dlg in synaptic clustering of Shaker $\mathrm{K}^{+}$channels in vivo. J Neurosci 17:152-159.

Wang YX, Wenthold RJ, Ottersen OP, Petralia RS (1998) Endbulb synapses in the anteroventral cochlear nucleus express a specific subset of AMPA-type glutamate receptor subunits. J Neurosci 18:1148-1160.

Wenthold RJ, Yokotani N, Doi K, Wada K (1992) Immunochemical characterization of the non-NMDA glutamate receptor using subunitspecific antibodies. Evidence for a hetero-oligomeric structure in rat brain. J Biol Chem 267:501-507.

Yamazaki M, Araki K, Shibata A, Mishina M (1992) Molecular cloning of a cDNA encoding a novel member of the mouse glutamate receptor channel family. Biochem Biophys Res Commun 183:886-892.

Zhao HM, Wenthold RJ, Wang YX, Petralia RS (1997) $\delta$-Glutamate receptors are differentially distributed at parallel and climbing fiber synapses on Purkinje cells. J Neurochem 68:1041-1052.

Zhao HM, Wenthold RJ, Petralia RS (1998) Glutamate receptor targeting to synaptic populations on Purkinje cells is developmentally regulated. J Neurosci 18:5517-5528.

Ziff EB (1997) Enlightening the postsynaptic density. Neuron 19: 1163-1174.

Zuo J, De Jager PL, Takahashi KA, Jiang W, Linden DJ, Heintz N (1997) Neurodegeneration in Lurcher mice caused by mutation in $\delta 2$ glutamate receptor gene. Nature 388:769-773. 